\title{
Interactive comment on "Multivariate autoregressive modelling and conditional simulation for temporal uncertainty propagation in urban water systems" by Jairo Arturo Torres-Matallana et al.
}

Anonymous Referee \#1

Received and published: 31 August 2020

The manuscript "Multivariate autoregressive modelling and conditional simulation for temporal uncertainty propagation in urban water systems" aims to select and characterize the main sources of input uncertainty in urban water systems and quantifying the contributions of each uncertainty source to model output uncertainty over time. It provides a good and well-structured example of an uncertainty analysis for a quite simplified model. Especially the results on CSO water quantity and quality are interesting and useful for further studies. In general, I think the manuscript is a valuable addition to the field with some minor discussion points I would like to bring up: 
Page 2 - Line 40: Is the minimization of CSO volume alone a goal in itself? There is the question if many events with a bad water quality (e.g. first flush) are better than fewer events with higher volume and better water quality? That may be a point for elaboration.

Page 12 - Line 261: As your model is quite simple and requires "little" computational time the chosen method is feasible, but that is not the case in most of those integrated studies. Is that not a limitation worth mentioning and discussing in 4.4? How could the approach look like in a more complex model?

Page 19 - Table 4: I quite like this very accessible and clear table for the decisionmaking of which input variables you select. Still, I think that the variables that are awarded ++ and + for uncertainty and sensitivity respectively must be discussed more. Especially I think that on the infiltration, NH4 in Rainwater, and C pervious where I don't necessarily agree with omitting them, at least not on the argues in the text of 3.1. On the other hand, I am surprised on the uncertainty of the total area. So, the distinction where the authors draw the deciding line in what to include into their analysis must be clearer. It could be maybe better explained by using graphical panels (e.g. in QUICS (Tscheikner-Gratl et al., 2017)) for illustrating that decision.

Page 29 - Line 560: You don't start with the accuracy of Monte Carlo Analysis (which is then 4.2) but with Uncertainty and water quality impact (4.1).

Page 31 - Line 588: I agree that that is one of the very valuable contribution of this paper. Still I would like to see some comparisons to other attempts on quantity (e.g. Sriwastava et al., 2018) and quality (especially measurements taken at CSOs the measured water quality at the WWTP influent is expected to render a low representativity of the conditions at the CSOs - e.g. Brombach et al.(2005); Diaz-Fierros T et al. (2002))

Printer-friendly version

Discussion paper

Page 32 - Line 62: The point about linkage is an important one, but I don't see the big input from this paper on the topic. Can you elaborate on this, why is the quantification at sub-module level advisable? Only due to the computational budget limitations? 
Page 34 - Line 701: Your abstract starts with "Uncertainty is often ignored in urban water systems modelling." I would have therefore expected and would like to read how this can be improved and how studies like yours can provide guidance for the decision makers.

Literature: Brombach, H., Weiss, G., Fuchs, S., 2005. A new database on urban runoff pollution: comparison of separate and combined sewer systems. Water Sci Technol 51, 119-128. https://doi.org/10.2166/wst.2005.0039 Diaz-Fierros T, F., Puerta, J., Suarez, J., Diaz-Fierros V, F., 2002. Contaminant loads of CSOs at the wastewater treatment plant of a city in NW Spain. Urban Water 4, 291299. https://doi.org/10.1016/S1462-0758(02)00020-1 Sriwastava, A.K., Tait, S., Schellart, A., Kroll, S., Van Dorpe, M., Van Assel, J., Shucksmith, J., 2018. Quantifying Uncertainty in Simulation of Sewer Overflow Volume. Journal of Environmental Engineering 144, 04018050. https://doi.org/10.1061/(ASCE)EE.1943-7870.0001392 Tscheikner-Gratl, F., Lepot, M., Moreno-Rodenas, A., Schellart, A., 2017. A Framework for the application of Uncertainty Analysis (Deliverable No. 6.7), QUICS. Zenodo, https://zenodo.org/record/1240926

Interactive comment on Hydrol. Earth Syst. Sci. Discuss., https://doi.org/10.5194/hess-2020342, 2020. 